\title{
QUEIMADURAS DE GUERRA
}

\author{
AULA PROFERIDA PELO \\ DR. JOSÉ MARIA DE FREITAS \\ NO CURSO DE MEDICINA MILITAR, PARA MEDICOS LIVRES \\ Professor de Técnica Cirúrgica da Escola Paulista de Medi- \\ cina - Livre Docente de Clínica Cirurgica da Faculdade de \\ Medicina da Universidade de São Paulo
}

A explanação do vasto tema do tratamento dạs queimaduras, sob todos os seus aspetos, principalmente se devessemos considerar as bases que o orientam, seria assunto incompativel com a finalidade deste curso que visa aplicação prática de principios bem estabelecidos para o tratamento de emergencia, nos primeiros socorros.

Para facilitar a explanação do assunto consideraremos a evolução clínica da queimadura de acôrdo com o estabelecido por Wiìson em 1935. Essa evolução clínica póde ser dividida em cinco períodos:

1 - Choque inicial.

2 - Choque secundário.

3 - Toxemia aguda.

4.- Infecção ou toxemia sética.

5 - Regeneração ou reparação.

Estes períodos podem ser distribuidos cronologicamente, segundo o esquema de Harkins: O choque inicial se estabelece imediatamente evoluindo dentro das primeiras 24 horas. $O$ período do choque secundário tem o seu máximo por volta da 48. ${ }^{a}$ hora. $\mathrm{O}$ período da toxemia aguda se estabelece a partir de 72 horas. A infecção começa depois dessas 72 horás, por volta do quarto dia. O choque inicial, que depende mais das condições em que a queimadura ocorre do que da própria extensão ou gravidade da lesão, é responsável, segundo Bailey, por 2 a $3 \%$ das mortes por queimaduras. Si este choque depende das condições em que se dá o acidente, ele não pode ser evitado. O indivíduo apezar do choque primário aparece ao médico com lesão limitada e pouco profunda, mas em estado de choque porque o susto, a dôr'; o pavôr do acidente durante uma ação aerea. durante o bombardeio de um navio ou mesmo na frente de batalha, foram fatores desencadeantes eficientes: Tal choque não pode ser evitado mas deve ser pronta e eficazmente combatido. Quasi concomitantemente com o choque primário ocorre o choque secundário, cujas causas podem (Beiley) ser resumidas na decomposição histamínica dos tecidos queimados, perda de plasma pela superficie quei- 
mada e não só para o exterior como tambem para a própria intimiclade tecidual, em virtude de um aumento de permeabilidade capilar, enxarcando-se os tecidos em redor do ponto queimado. A consequência da perda de plasma é a redução do volume do sangue circulante. Com isso há quéda da pressão arterial; esta, por si, acarreta anoxia que vae aumentar ainda mais a permeabilidade capilar de maneira'generalizada e então cresce a quantidade de plasma que se evade da rede circulatória estabelecendo-se o círculo vicioso. Como consequência o choque se agrava constantemente. Nas queimaduras não ha perda de globulos e sómente de plasma: porisso ha uma superconcentração do sangue, índice de valôr para o cálculo da quantidade de fluido que deve ser infundida, afim de compensar a evasão, levantando a pressão, melhorando a anoxia, portanto concorrendo para a parada do círculo vicioso.

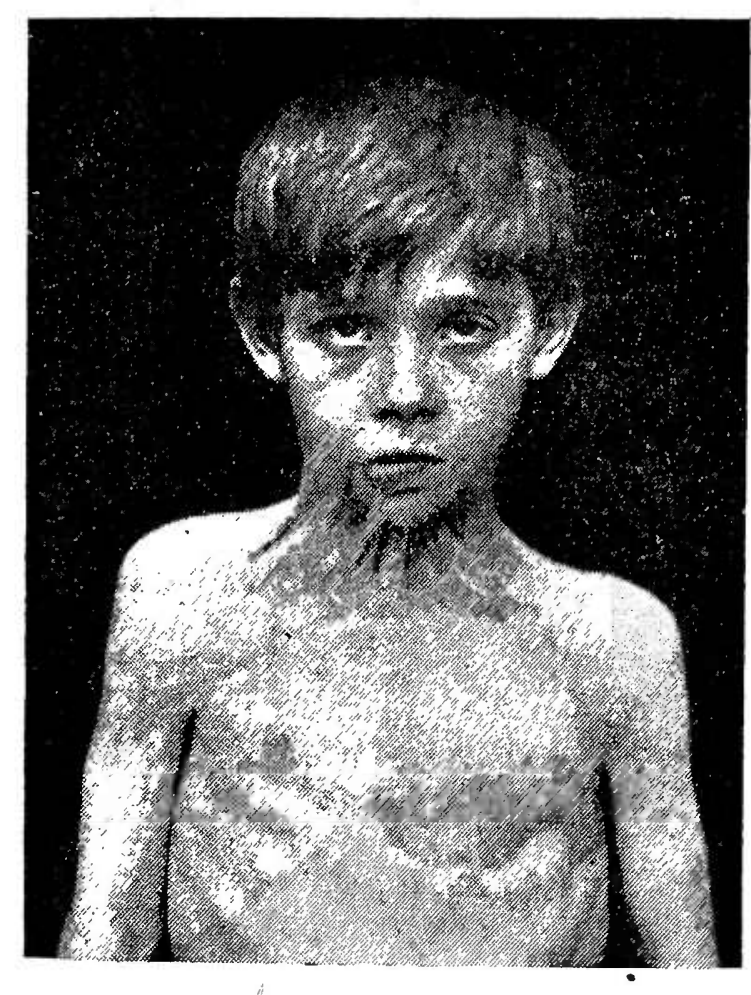

FIG. 1

Contraturas devidas a queimaduras extensas do $3 .^{\circ}$ grau.

BEILEY - Surgery of modern warfare.

O choque secundário é grave. Segundo Beiley é responsável por $80 \%$ das mortes por queimaduras. Atkins, referindo-se aos queimados evacuados de Dunquerque diz que o choque foi o maior inimigo e matou $60 \%$ dos acidentados em tal emergência.

$\mathrm{O}$ estado de toxemia aguda, como vimos, se estabelece por volta

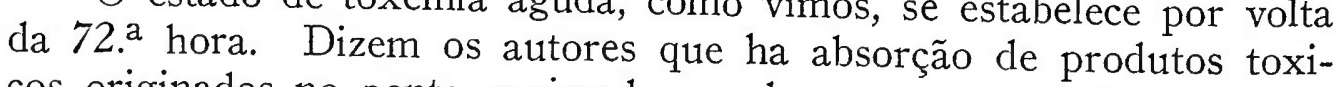
cos originados no ponto queinado, produtos que veiculados pela circulação provocam alterações principalmente nos órgãos parenquima- 
tosos, entre eles o fígado. O quadro clínico dominante nesta fase é o da ansiedade, agitação hipertermia, pulso rápido e fino, cefaléia e muitas vêzes icterícia que denuncia o comprometimento hepático.

A toxemia septica é a fase da infecção. Hoje, num queimado tratado, segundo regras bem estabelecidas e em tempo oportuno, a fase da infecção não deve ocorrer. Isso, nem sempre; entretanto, é possivel na guerra, em que, muitas vêzes, os primeiros socorros chegam tarde demais. Sabemos que a queimadura é uma ferida amplamente aberta e, segundo as regras de Friedrich, a partir da 6 . $^{\text {a }}$ hora a ferida deve ser considerada infectada e não simplesmente contaminada.

Enfim a fase de reparação ou restabelecimento. Não se deve entender por cura apenas a reparação das lesões, com cobertura da zona queimada por uma camada de tecido seco, porém contraido, deformado e inelástico. (Fig. 1) O conceito de cura deve ser mais. elevado: será necessário que a parte lesada tenha função normal e revestimento natural.

A observação destas etapas evolutivas permite o estabelecimento de um certo número de princípios considerados fundamentais no tratamento de uma queimadura. Estabelecidos esses princípios, a discussão do gráu, a avaliação exata de sua extensão, a escolha deste ou daquele método como método de eleição, passam para um segundo plano. Estes princípios de regra conhecidos por todos, são muitas vêzes esquecidos diante do caso concreto de um indivíduo queimado. Porisso pretendo chamar a atenção para eles, frizando a sua importância.

Os princípios fundamentais para o tratamento de uma queimadura decorrentes do conhecimento da evolıção das lesões podem ser esquematizados nos seguintes itens:

1 - Prevenir e combater o choque.

2 - Converter a queimadura contaminada numa ferida limpa.

3 - Cobrir a zona queimada pelo curativo mais simples capaz de:

a) Proteje-la do risco constante de reinfecção.

b) Poupar toda e qualquer porção de péle ou subcutaneo ainda viavel.

c) Assegurar a drenagem do serum que exsuda, até que a exsudação pare por pressão ou coagulação. mada.

d) Exercer pressão moderada e uniforme sobre a parte queibaixo delè.

e) Ser facilmente removido se a infecção se estabelecer por

4 - Por em repouso a parte lesada.

5 - Assegurar a cura em tempo mínimo e com a menor perda de função. 
$\mathrm{Na}$ aplicação desses princípios fundamentais devemos considerar as fases da queimadura que podem ser evitadas e as que sómente podem ser tratadas.

Como já vimos, o choque primário não pode ser evitado mas deve ser tratado prontamente. $\mathrm{O}$ meio mais eficaz, a terapêutica heróica do choque primário nas queimaduras, é a morfina. A morfina tem sido usada e preconizada entre outros por Beiley, que estabelece a dose de 1 a 2 centigramas, repetida depois das primeiras duas horas, si o doente ainda se queixa. Sauerland, chefe do serviço médico do couraçado Deutschland que foi bombardeado na revolução espanhola, teve grande número de queimados a bordo e lançou mão de injeções de morfina endovenosamente, ( 0,007 grs.), considerando o tratamento eficaz. Mas não é sómente a morfina a terapêtutica do choque primário: aquecimento entra como medida complementar. A administração de fluidos, si possivel abundantemente é aconselhavel por via oral.

O tratamento do choque secundário, que, em parte pode ser evitado, se apanhamos o queimado imediatamente depois do acidente que provocou a queimadura, e conseguimos diminuir a evasão de plasma (causa principal do estabelecimento desse choque); de um modo geral, tern como objetivo restabelecer o volume do sangue circulante, manter a taxa de cloretos e suster a perda do plasma. Isso pode ser realizado com medidas de ordem geral e medidas de ordem local. As medidas de ordem local, serão discutidas daquí a pouco quando tratarmos do curativo das queimaduras. As medidas de ordem geral devem ser consideradas em função do conhecimento de que a redução de volume de sangue se faz a custo da perda de plasma. O plasma é pois sua terapêutica heróica. A injeção de plasmạ deve ser considerada quantitativamente para cada caso. Não basta dizer que se injeta plasma: é preciso saber quanto de plasma é necessário injetar. Ha duas regras propostas para se calcular a quanticlade de plasma a injetar: $1 .^{\mathrm{a}}$ ) Consiste em administrar tantos $50 \mathrm{cc}$. de plasma quantos forem as unidades por cento da superficie corporal queimada. Essa superficie corporal queimada póde ser avaliada pela tabela de Barkow. Estabelecida, por exemplo, a queimadura de $20 \%$ da superficie corporal, temos que $20 \times 50 \mathrm{cc}$. é a quantidade de plasma a ser injetada. Esta não deve ser injetada de uma só vez e sim em três vêzes: nas duas primeiras horas, um terço; um terço nas 4 horas seguintes e mais'um terço nas 6 horas restantes pois que, em 12 horas, o paciente deve ter recebido a quantidade total de plasma. Esta regra foi substituida por Harkins em trabalho bem documentado sobre o tratamento das queimaduras. Harkins manda administrar $100 \mathrm{cc}$. de plasma para cada ponto de leitura ao hematocrito, acima da relação normal de 44 ou 45 . Aquí ocorre considerar que nas emergências de guerra, nos postos avançados de socorro, não exista hematocrito; a tabela de Barkow que póde ser transportada num papel, deve ser usada. Desde que haja um laboratório onde possa ser determinada a relação do plasma e 
globulos, podemos usar a segunda formula. Harkins, estabelece tambem que no tratamento do choque secundário é importante o equilíbrio cloretado, mas que, nas queimaduras, a administração de um litro de sôro fisiológico diariamente é suficiente para mante-lo, a não ser que alem da perda de líquidos pela superficie queimada, o indivíduo perca cloretos de outra forma, seja por vomitos, ou por outra razão. Neste caso, a dose de um litro em 24 horas já não é suficiente, porem existem meios de se determinar qual a quantidade de cloretos necessária para o indivíduo em tais condições. Não discutiremos aquí o assunto.

Como método complementar de tratamento do choque secundário, - a anoxia aguda é fator de permeabilidade capilar aumentada - administração de oxigenio está indcada em todos os casos graves. Alem disso a administração de extrato suprarrenal não deve tambem ser esquecida.

A prevenção e tratamento da infecção se fazem de regra, pelos cuidados locais. A infecção deve ser combatida pelas medidas consubstanciadas no item 2 dos princípios fundamentais: Converter a zona queimada numa ferida limpa; e no item 3; cobrir a zona queimada pelo curativo mais simples, etc.. Com a adopção de tais medidas teremos evitado o perigo da fase de toxemia sética ou a infecção. Admitamos entretanto que, a fase de infecção se estabeleça, ou porque o queimado foi socorrido tardiamente ou porque métodos intempestivos foram aplicados e que perturbaram a boa observância dos princípios fundamentais estabelecidos: aquí a sulfamida representa um ótimo elemento de combate à infecção. ' $E$ ' preciso não esquecer porem que a sulfamida age sobre o fígado e que já por si a toxemia aguda se revela por lesões hepáticas; então todas as precauções. para que a sulfamida não agrave as lesões, devem ser tomadas: administração de glicose hipertônica, antitóxica, etc. Alem disso a taxa de proteinas deve ser mantida, o que se consegue com a transfusão de plasma.

Isso visto passemos às medidas locais ou tratamento local das queimaduras. Com a ansia de crear novos métodos ou de aplicar o último método publicado o cirurgião se esquece muitas vêzes de determinados princípios e daí o insucesso de muitos no tratamento das queimaduras.

Para converter a ferida contaminada em ferida limpa, uma condição preliminar e indispensavel: a abolição completa da dôr, o que se consegue de regra, exclusivamente com a administração de morfina. Não se deve nessa fase preparatória do tratamento local das queimaduras, usar a anestesia geral, principalmente na guerra, em que os métodos de anestesia por gazes só são possiveis nos hospitais das cidades. As anestesias gerais, de regra, são de grande ação tóxica para o fígado. Allen, de Chicago, discutindo o emprego da anestesia e das mortes que se verificam no período da toxemia aguda em que as lesões hepáticas são graves, diz que a maioria dos indivíduos mortos nesse período tomou anestesia em dose alta no trá 
tamento inicial da queimadura: portanto, talvez não se deva atribuir sómente às queimaduras as lesões do fígado, cabendo ao anestésico papel importante nessa lesão. Por isso é aconselhavel não usar a anestesia geral, porem sómente a morfina nesta primeira fase.

Consiste o ato, em si, em remover todos os detritos de vestes queimadas e outros que existam sobre a queimadura; abrir todas as flictenás; ressecar ou retirar com pinça as partes de péle necrosada e destacada, evitando todo e qualquer sangramento. Esta limpesa, se nenhum tratamento foi ainda feito, ou se a queimadura. não ocorreu em circunstância que em geral são frequentes na marinha - superficie queimada revestida de óleo e agravada a situação pelo contacto com água salgada, - não se deve usar na limpesa nem benzina nem éter: sempre água esterilizada, sabão, e não usar escova que provoca traumatismo desnecessário. A limpesa deve ser feita com tampões de algodão esteril e, o que é mais importante, em ambiente aseptico. Aquí, diz Allen: "A infecção das queimaduras é mais grave pela mão desprotegida de quem as trata, pelas bocas e narizes descobertos, do que pelo próprio acidente que a provocou'. A limpesa deve ser feita em ambiente asséptico, tal como se faz uma intervenção abdominal. Terminada a limpesa ocorre aplicar o curativo que proteja a ferida do risco - constante de reinfecção.

No tratamento local para estudo e descrição dos métodos de curativos, vamos dividí-los em dois grupos: Os que dependem da tanagem e os que dela não dependem.

1 - Os que dependem de tanagem foram idealizados por $\mathrm{Da}$ vidson em 1925, com uma solução de ácido tânico a 2,5\%. O ácido tânico tem a propriedade de provocar a formação de uma crosta sobre a zona queimada, crosta que por cobrir integralmente a lesão, a protege seguramente dos riscos da reinfecção e que tem grande valôr de evitar a perda de plasma para o exterior, mas que não evita a evasão do plasma para os interstícios celulares. Assim o método de tanagem visa tambem o tratamento do choque secundário, porque evita a absorção de produtos que se forman no local. A aplicação do ácido tânico, segundo Davidson não é realizavel na guerra. $\mathrm{O}$ ácido tânico puro precisa ser passado 4 ou mais vêzes e isso é demorado, o que na emergência de numerosas queimaduras junto com outros ferimentos, torna o método impraticável. Em 1935, Bettmann associou o nitrato de prata à tanagem. A aplicação de uma solução de ácido tânico, para Bettmann a $5 \%$, seguida 5 minutos depois de uma pincelagem de nitrato de prata a $10 \%$, apressa a formação da crosta que fica mais rija e permite ganho de tempo. Apresenta entretanto um inconveniente: a crosta muito rija, muitas vezes se parte e pelas fendas resultantes ocorre o perigo da reinfecção. Alem do mais, a tanagem, segundo Bettmann, provocando uma crosta muito rija, está contra indicada formalmente nas zonas articulares, na face e nas mãos porque, esta acarreta deformações, perda de função, que devem ser constantemente evitadas para que esteja preenchido o $5 .^{\circ}$ item dos princípios fundamentais do tratamento. 
Em. 1929, Aldrich indicou para a tanagem um método de violeta de genciana em solução de $2 \%$. A violeta de genciana tem sobre o ácido tânico uma dupla vantagem; em primeiro lugar a crosta decorrente 'da aplicação da violeta de genciana é mais elástica e portanto mais aplicavel nas zonas articulares, na mão e na face. Alem disso ela tem uma ação muito evidente sobre os germes grã positivos e portanto auxilia o combate de prevenção à toxemia sética. O próprio Aldrich em 1933 associou à violeta de genciana o verde brilhante e acri-flavina, empregando o que os ingleses chamam de triplice mistura. A associação de violeta de genciana, do verde brilhante e da acri-flavina, torna a mistura eficiente não só contra os germens grãpositivos como tambem contra os grã-negativos, sem aumentar a rigidez da crosta, sendo porisso aplicavel à face e às mãos. Beiley no capítulo sobre queimaduras do seu recente livro apresenta o seguinte caso. (Fig. 2)

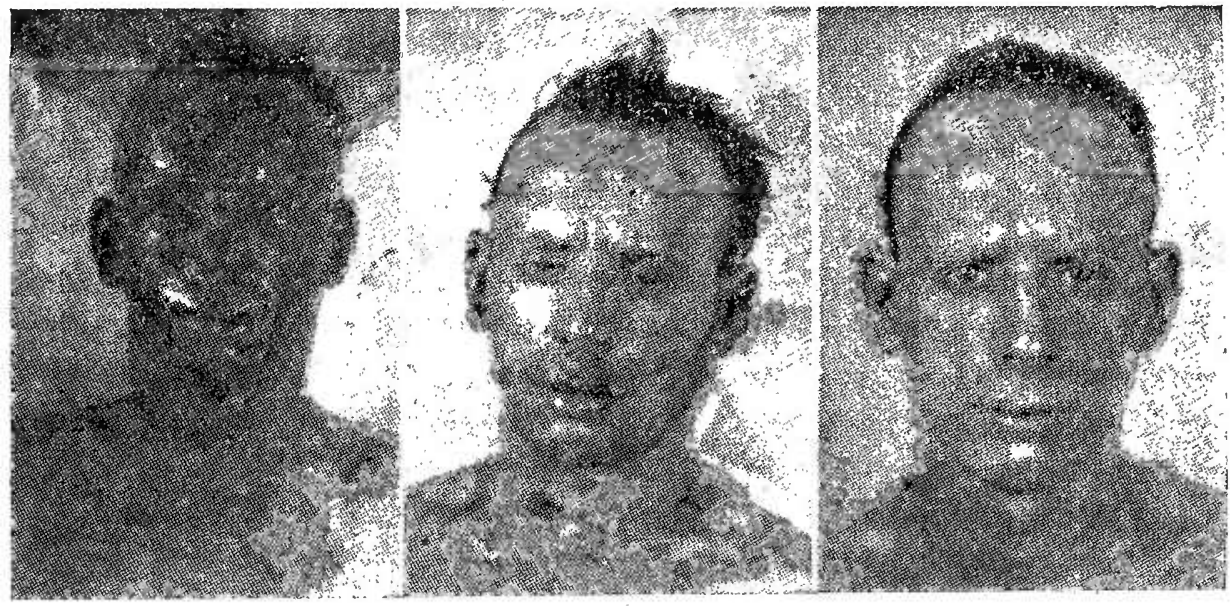

FIG. 2

Queimadura-da face tratada com banho salino e triplice mistura. As fotografias foram tiradas com 5 dias de intervalo.

BEILEY : - Surgery of Modern Warfare.

Esse método póde ser aplicado na face como nas mãos, com ótimos resultados. (Fig. 3 ).

Os métodos que dependem da tanagem, principalmente com a utilização do ácido "tânico, pelos bons resultados proporcionados, foi usado e abusado, sendo tal o abuso que em Outubro de 1940 o estado maior de saúde do exército inglês publicou uma circular condenando o uso da tanagem com ácido tânico na face e nas mãos, chamando a atenção para os resultados que classificava de desastrosos, do emprego do método em tais circunstâncias, 1 - mão e face.

2 - Ainda no tratamento local devemos considerar os métodos que não dependem da tanagem. Os mais antigos são os que usam pomadas, en yeral condenadas, tolerando-se apenas o óleo de fígado de bacalháu em virtude da ação benéfica da vitamina $A$ e $D$ sobre a epitelização. Os banhos salinos alternados con curativos salinos, 
método recomendado pela circular do E.M.S. a que já nos referimos, dão bons resultados. Allen e Koch do Cook County Hospital, de Chicago preconizaram o emprego de um método que eles chamam de curativo não aderente e compressivo. O método geral de tratamento proposto por Allen é o seguinte: limpesa, cobertura da area queimada com compressas de gaze embebida em vaselina líquida. Aquí ocorre considerar que apezar de se usar a vaselina, que seria um produto contra indicado, gorduroso, os resultados de Allen são muito bons. Sobre essa camada de gaze vaselinada, cuja finalidade é impedir que o curativo adirá à superficie queimadia, ele

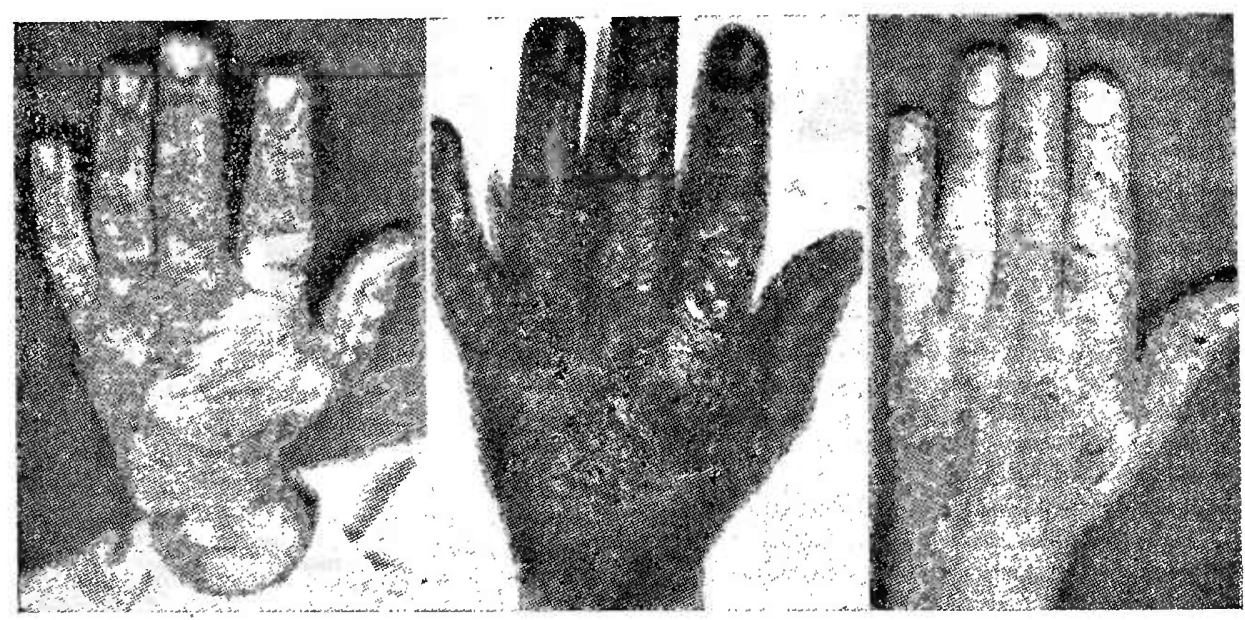

FIG. 3

Queimaduras do $2 .^{\circ}$ grau na mão tratada com banho salino e triplice mistura. BEILEY - Surgery of Modern Warfáre.

coloca uma série de 6 a 8 laminas de gaze e sobre elas mechas de un tecido esponjoso que possa realizar por meio de uma atadura elástica, una compressão moderada sobre a ferida, e deixa nessas condições o curativo por um espaço de 12 a 14 dias, realizando ad mesmo tempo o repouso da parte lesada por meio de uma imobilização por talas. Os resultados por ele obtidos são maravilhosos e comparados aos obtidos com os métodos anteriormente usados da tanagem. (Figs. 4 e 5) $\mathrm{Na}$ enfermaria de crianças, onde ele trabalhou, foram tratados 395 casos de queimaduras com ácido tânico com 10\% de morte; o método de Bettmann deu $7 \%$ de morte; o método que ele descreve deu em 1939. 5,8\%, de 1940 3,65\%, e em $19412,7 \%$ de mortes. Como vemos, a mortalidade caiu sempre e ele considera isso como decorrente dos cuidados acessórios de enfermagem e mudança de curativos porque uma queimadura mais profunda, tratada por esse método o curativo não pode ser único. Quanto maior e mais profunda a superficie queimada, maior a dificuldade de cicatrização espontânea. Como a cura deve ser em tempo mínimo, o enxerto, nesses casos é necessario. Mas até que o tecido esteja bom para receber o enxerto, o curativo deve ser mudado de 48 

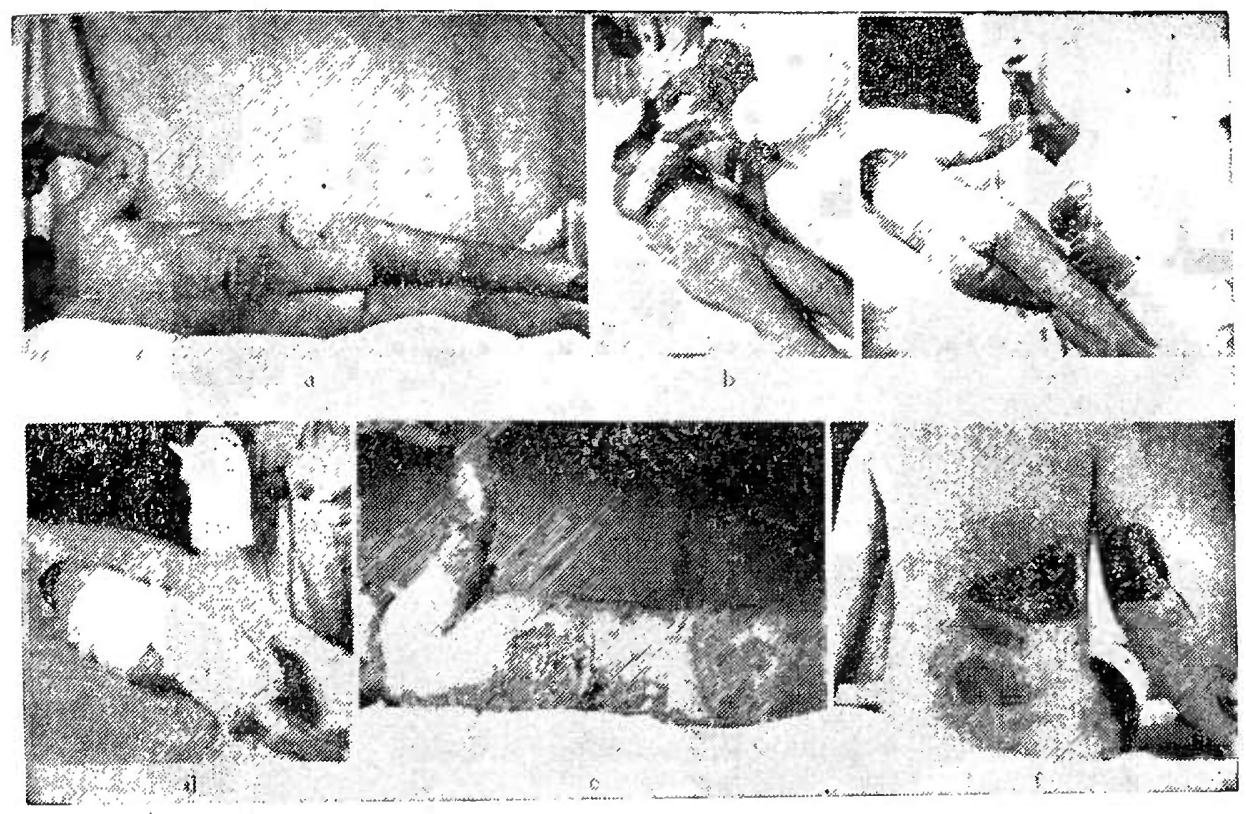

FIG. 4

Queimadura com areas extensas de destruição profunda. a) Por ocasião da entrada; b) limpeza das superficies queimadas; c) excisão de tecidos necrosados; d) aplicaçāo do curativo compressivo; e) deois de levantado. $10^{\circ}$ - curativo no $13 .^{\circ}$ dia; f) aspeto da queimadura no $20.0^{\circ}$ dia em condições de receber o enxerto de péle

ALLEN, H. S. and KOCH, S. L.: Surg. Gynec. \& Obst. 74: $914-1942$.
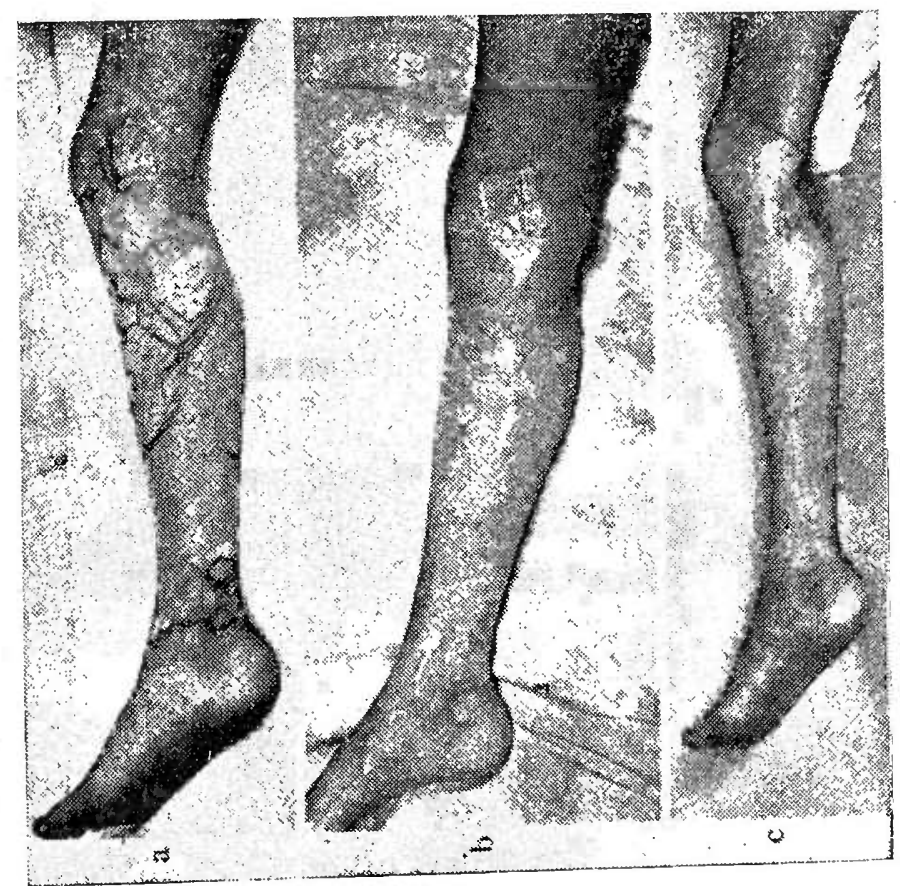

FIG. 5

Queimadura extensa com perda parcial de espessura da péle a) $\mathrm{Na}$ admissão; b) após avagem e resecção péle. a) Nositalisados; c) Por ocasião da alta, 14 dos tecidos desvitas após a queimadura.

ALLEN, H. S. and KOCH, S. L.: Surg. Gynec. \& Obst. 74: 914 - 1942. 
em 48 horas; nessas mudanças ele cobre a superficie com gaze fina para impedir que os brotos de tecido neoformado penetrem nas malhas da gaze; sobre essa camada, coloca o curativo compressivo. Este tem a finalidade no primeiro curativo, de evitar a evasão do plasma e depois de facilitar a circulação linfática e sanguinea.

Este método requer a hospitalização porque số em ambiente cirúrgico a limpesa e a aplicação desse curativo póde ser realizada e mantida asséticamente. O proprio Allen aconselha, embora não tenha experiencia, a aplicação da sulfamida local, como primeiro curativo de emergencia de guerra e para a aplicação de sulfamida local, dois métodos podem ser utilizados: ou a sulfamida em pó, ou em pomada; essa pomada deve ser preparada com um veículo não gorduroso, com uma mucilagem capaz de permitir que, removido o paciente para o hospital onde possa ser definitivamente tratado, seja removiclo o primeiro curativo sem dificuldades e possa ser usada a aplicação de um dissolvente de gorduras, o que deve ser feito neste caso. Allen e Owens, trataram 4 individuos com unguento de sulfatiazol e puderam demonstrar que o emprego da stulfanida sobre una larga superficie queimada não apresenta perigo de absorção maciça, porque a sulfamida com o exsudato da queinadura forma uma crosta que pára a absorção e, nos casos que eles estudaram a taxa de sulfamida no sangue, não atingiu niveis elevados, capazes de provocar a intoxicação. Wallace depois da divulgação da circular já citada do exercito inģlês, condena o emprego dos métodos de tanagem em virtude do pânico que se estabeleceu, visto que a imprensa leiga tamben divulgou a circular na Inglaterra. Prociriou então en colaboração com outros, um método de tratamento que désse resultado eficiente, e considerando principalmènte os casos que na Inglaterra chamam queimaduras dos homens do ar, porque na explosão do avião uma reação de defesa do individuo é levar as mãos para proteger o rosto, queimando-se rosto e mãos ao mesmo tempo. Ficou estabeleciclo que o melhor método para o tratamento das mãos é a aplicação de una geleia de albucid a $5 \%$ em glicerina e caolim em partes iguais, á qual se póde adicionar $10 \%$ de oleo de figado de bacalhau. Esse foi considerado o mais eficiente e conveniente.

Finalmente temos o $4 .^{\circ}$ item, de por em repouso a parte lesada. Este item é aconselhavel por varios motivos, entre os quais o de não provocar na zona em regeneração, traumatismos que façam com que aumente o aparecimento de teciclo fibroso, dando em consequencia a cicatriz viciosa. Aqui ocorre considerar o método preconizado por Zeno da Argentina de, após a limpesa do curativo, aplicar imediatamente um aparelho gessado que preenche varios requisitos: proteje a ferida contra a reinfecção, asssegura a exsudação do serum entre a superficie queimada e o curativo, produz a compressão e reduz a exsudação do plasma, mas apresenta o inconveniente: a remoção é mais dificil para o tratamento, se o estado geral faz supôr uma infecção. 
Finalmente ocorre obter a cura em tempo minimo. Esta, nas queimaduras graves, do terceiro gráu, só se consegue por meio dos enxertos. Não vamos descrever aqui os métodos de enxerto, porque isso já escapa ao tratamento de emergencia. Ele só pode ser feito em hospitais, por cirurgiões de carreira.

Tendo em mente estas considerações e a aplicação religiosa dos principios estabelecidos, espero que todos vós possaseis em qualquer logar onde estiverdes na emergencia de uma guerra, realizar obra util a serviço da Patria e em beneficio da humanidade assolada pelos horrores das ações belicas.

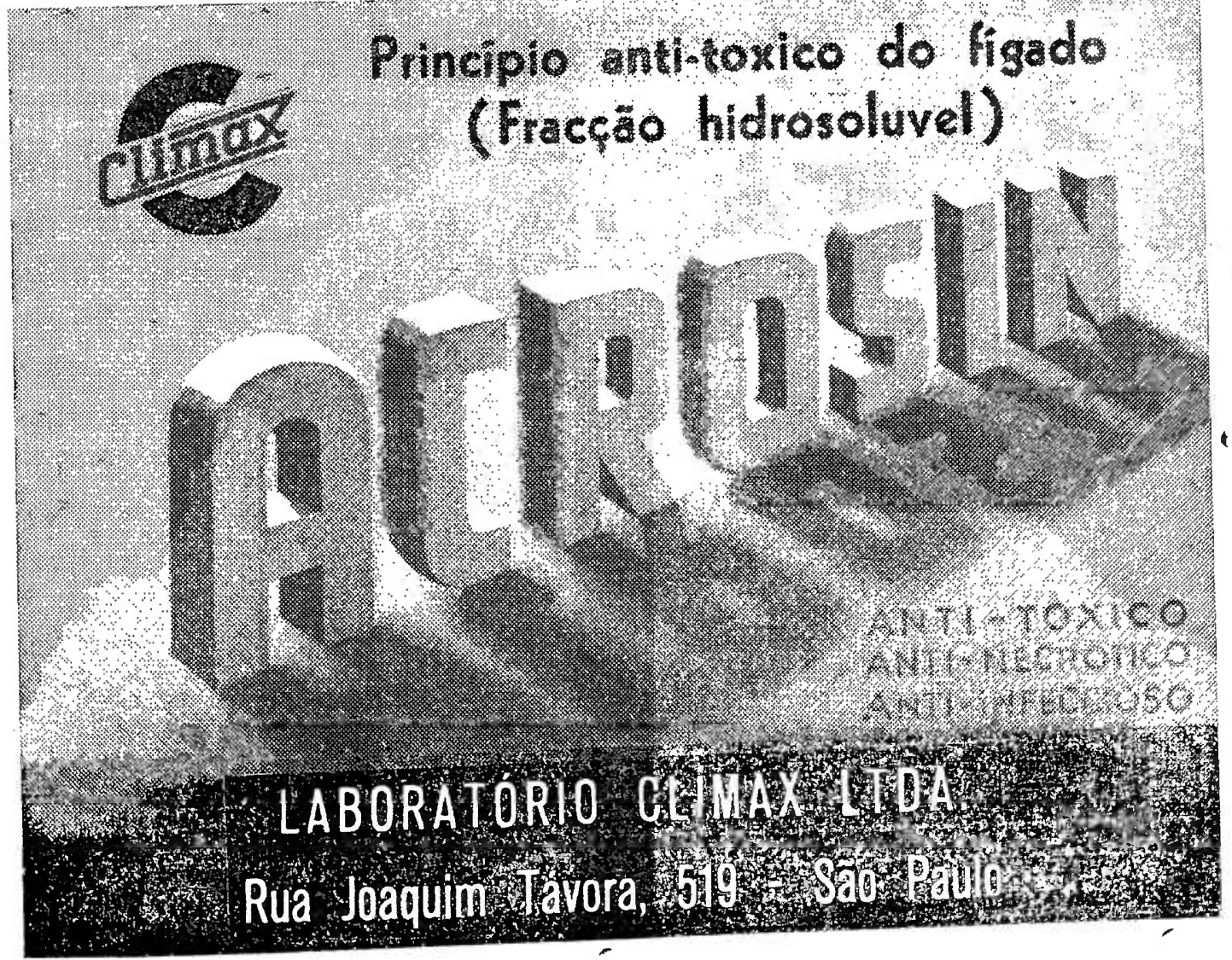




\section{Anticonvulsivo para o tratamento da epilepsia}

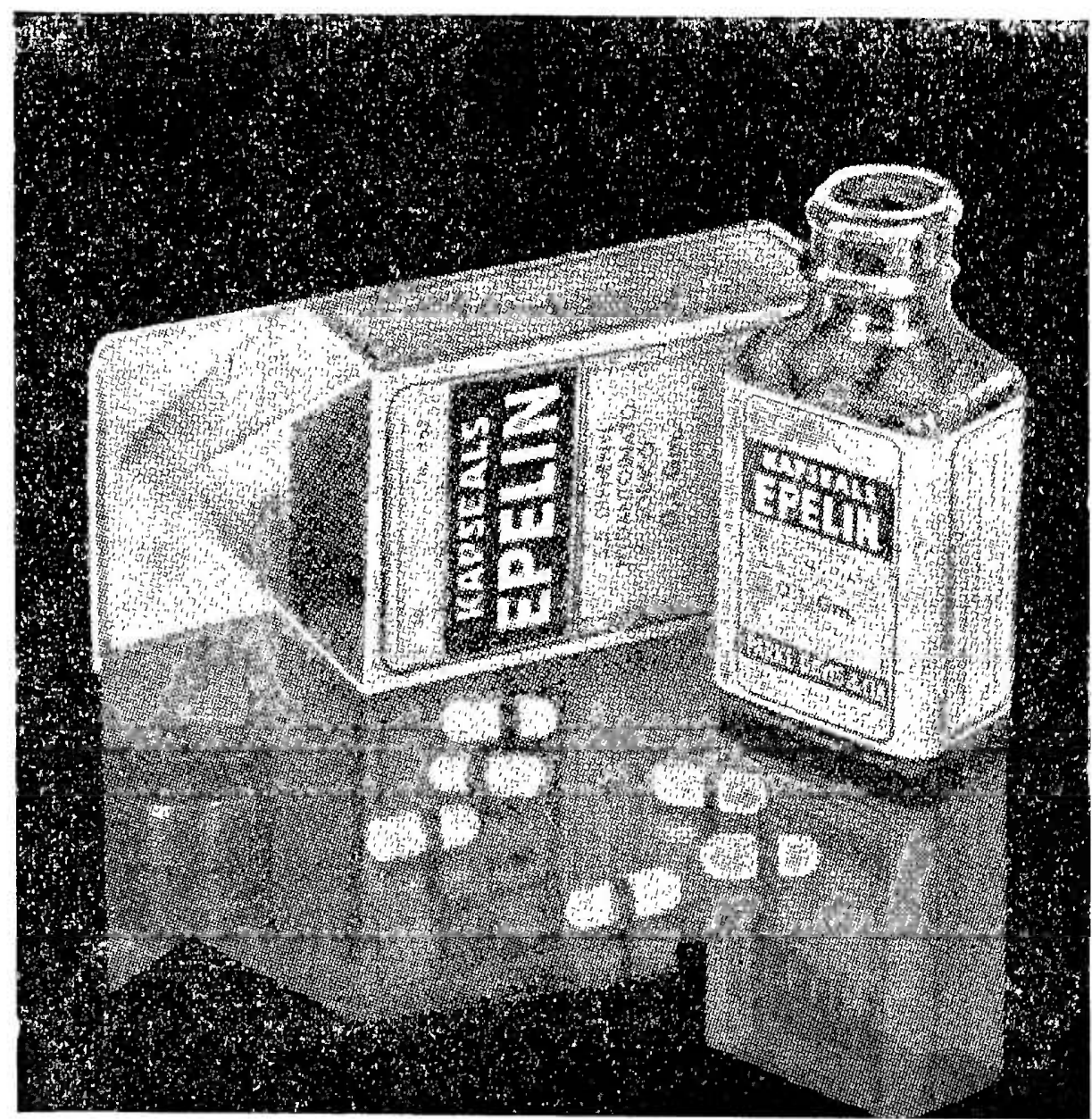

KAPSEA LS

\section{EPELIN *}

(5,5 - diphenyl hydantoinato sodico)

\section{O PRODUTO ORIGINAL}

EPELIN é um novo anticonvulsivo, praticamente destituido de effeito hypnotico. Superior em actividade aos bromuretos e barbituricos, sem os inconvenientes destes. Previne ou diminue grandemente a incidencia e o rigor dos ataques convulsivos na maioria dos epilepticos.

EPELIN -é indicado no tratamento das syndromes convulsivas e epilepsia, especialmente nos casos refractarios a outras medicações.

Apresentado em vidros de 30 Kapseals (capsulas selladas) de 0,1 gm.

\section{Parke, Davis \& Companhia}

Rua Marquez de S. Vicente, 99/103

RIO DE JANEIRO

* EPELIN denomina-se DILANTIN SODIUM nos E. U. A. e EPANUTIN na Inglaterra, todos fabricados exclusivamente por Parke, Davis \& Cia. 